\title{
Strengthening public health services to achieve universal health coverage in China
}

\section{Better integration of public health and medical services and greater focus on quality of services are needed to make further progress on health outcomes, say Beibei Yuan and colleagues}

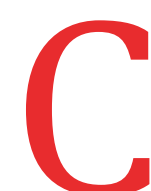
hina's Equalization of Basic Public Health Services (EBPHS) policy sets out financing and governance measures designed to ensure access to health services for all its citizens. ${ }^{1}$ EBPHS is one of five priority areas for action in the comprehensive health system reform launched in 2009 in China, with a target date of 2020 to achieve universal health coverage. ${ }^{2}$

Primary health providers provided some public health services before 2009 (table 1), and these services have contributed to improving maternal and child health and controlling infectious diseases. However, providers lacked the funding, motivation, and capacity to expand public health services to deal with the full range of public health problems and new challenges from chronic disease. This was a major constraint to promoting universal coverage of essential health services. Here we consider what the EBPHS has achieved since its introduction in 2009 and its future challenges.

\section{KEY MESSAGES}

- The equalisation of basic public health services policy aims to promote universal health coverage through strengthening the public health system

- The policy has increased coverage and reduced disparities between areas of lower and higher economic development, although progress varies among services

- The policy does not give enough attention to quality of public health services, especially management of non-communicable diseases

- To accelerate progress the EBPHS policy should seek to achieve a better match between services package and funding levels, create appropriate incentives for health providers to improve the quality of care, and promote better synergy between public health initiatives and health services

\section{Key elements of EBPHS policy}

The EBPHS has two strands covering basic public health services and targeted public health programmes, each with different methods of finance and delivery (table 1). The basic public health services package sets out the minimum services for all citizens. The packages do not include any medical treatment, only monitoring and other management. The initial package of nine categories in 2009 had been expanded to 14 categories by 2017 (table 1). Local governments can expand the minimum package based on local population's health problems and the government funding at their disposal. Primary healthcare institutions (box 1) are responsible for delivering these services to all residents, free at the point of use. The costs are shared between central and local government, with a minimum funding for the basic package of $¥ 15$ (€1.70; €2; \$2) per person in $2009^{3}$ and $¥ 55$ in 2017.4

In addition to the basic health services package, crucial public health programmes seek to counter important infectious diseases and meet the needs of disadvantaged populations (table1). These services are funded primarily by central and provincial governments and delivered by public health institutions. ${ }^{13}$

EBPHS sought to achieve universal availability and promote a more standardised delivery of health services to all citizens. To achieve this governments earmarked funding to cover the full costs of the basic service package (the accumulated government input reached $¥ 300$ bn in $2016^{4}$ ). The minimum funding per capita increased by $17.6 \%$ a year on average from 2009 to 2017, greater than the average annual increase in total health expenditure (14.1\%) over this period. ${ }^{5}$

To ensure that all primary healthcare institutions got the minimum required funding, central government contributed more funding to less developed regions, where local government's budgets are more constrained (table 2). In addition, the central government issues national guidelines for each type of service ${ }^{6}$ and organises regular training to support their use, especially supporting less qualified health providers, such as village doctors. Lastly, EBPHS strongly emphasises the need to track performance and has designed explicit performance targets to ensure the uniform enforcement of the service packages.

Central government allocates funding for training ( $¥ 80 \mathrm{~m}$ a year) and performance assessment activities ( $¥ 65 \mathrm{~m}$ a year). ${ }^{4}$

Progress towards service coverage and equity Two measures were selected to assess the changes in coverage and equity after implementation of the EBPHS-child health surveillance and management of type 2 diabetes. Both are also indicators for monitoring universal health coverage. ${ }^{7}$ Child surveillance is key to improving children's health, a widely accepted measure of health system performance. Management of type 2 diabetes reflects the increasing burden from non-communicable diseases. Another reason for choosing these measures was that data were available before and after implementation of EBPHS, enabling examination of national trends. Given that the two measures are core services, their coverage and equity trends are likely to reflect the consequences of implementation of EPBHS.

The child surveillance programme, which comprise newborn home visits, regular physical examination, and promotion of child growth, expanded from covering $74.6 \%$ of all children under 3 years in 2008 to $90.9 \%$ in $2016 .{ }^{5}$ Figure 1 shows the narrowing gap in coverage across regions with different economic development.

The management of patients with type 2 diabetes includes screening, regular follow-up, and health education. The number of patients covered increased from 18.5 million in 2011 to 31.2 million in 2017 (fig 2). ${ }^{8}$ The average annual increase in patients coved was $7.3 \%$, which is higher than the average annual increase in the number of patients with diabetes $(4.1 \%)$ over the same period. ${ }^{9}$

However, the rate of increase in coverage was not linear, stalling in 2013 before rising 


\begin{tabular}{|c|c|c|c|c|}
\hline & \multicolumn{2}{|l|}{ Basic public health services } & \multicolumn{2}{|l|}{ Public health programmes } \\
\hline & Before 2009 & Added after 2009 & Before 2009 & Added after 2009 \\
\hline $\begin{array}{l}\text { Available } \\
\text { services }\end{array}$ & $\begin{array}{l}\text { - Child health surveillance (0-36 months) } \\
\text { - Maternal health } \\
\text { - Vaccination } \\
\text { - Reporting and handling of infectious } \\
\text { diseases }\end{array}$ & $\begin{array}{l}\text { - Establishing health records for all citizens } \\
\text { - Health education } \\
\text { - Care for older people } \\
\text { - Hypertension and type } 2 \text { diabetes } \\
\text { - Severe mental illness } \\
\text { - Coordination of health and hygiene } \\
\text { monitoring (eg, food safety; from 2011) } \\
\text { - Traditional Chinese medicine (2015) } \\
\text { - Tuberculosis (2015) } \\
\text { - Free contraceptives (2017) } \\
\text { - Health literacy and smoking cessation (2017) }\end{array}$ & $\begin{array}{l}\text { Prevention and control of tuber- } \\
\text { culosis and AIDS } \\
\text { National immunisation pro- } \\
\text { gramme } \\
\text { Rural facility delivery } \\
\text { Cataract surgery for poor patients } \\
\text { Reconstructing water supply and } \\
\text { lavatories } \\
\text { Eliminating endemic fluorosis }\end{array}$ & $\begin{array}{l}\text { Hepatitis B vaccine for } \\
\text { children under } 15 \text { years old } \\
\text { Folic acid supplements before } \\
\text { and during early pregnancy } \\
\text { Breast and cervical cancer } \\
\text { screening for rural women }\end{array}$ \\
\hline Financing & $\begin{array}{l}\text { Unstable, limited programme based } \\
\text { budget from different levels of } \\
\text { governments and dependent on local } \\
\text { government's finance }\end{array}$ & $\begin{array}{l}\text { Funds collected from the central and local } \\
\text { governments; higher national payments to less } \\
\text { developed regions }\end{array}$ & \multicolumn{2}{|c|}{$\begin{array}{l}\text { Funds are mainly collected from central and provincial govern- } \\
\text { ment; less developed regions receive higher national payments }\end{array}$} \\
\hline
\end{tabular}

again after $2015 .^{10}$ Possible explanations for this are lack of accurate data because many patients with diabetes are not diagnosed and a lack of comparability across different years with more patients being detected through EBPHS. ${ }^{11}$

Figure 3 shows that inequalities in coverage of diabetes management remain between regions with different socioeconomic development, although the differences have narrowed considerably. ${ }^{71213}$ The coverage of diabetes management is higher in the western areas with lowest economic development, mainly because of larger and timely subsidies to these areas by the central government.

\section{Strengthening EBPHS}

Moving forward, EBPHS should focus on quality of services to ensure future progress. Using health outcomes as a proxy indicator for service quality, different trends were found for child health and diabetes: mortality of children under 5 years fell from 20.6/1000 in 2008 to 13.3/1000 in $2016 .{ }^{5}$ However during this period mortality from non-communicable diseases increased from $4.8 / 1000$ to $5.7 / 1000 .^{14}$
Blood glucose control in patients with diabetes reflects the quality of services for noncommunicable diseases. Data show that the control rate has remained persistently low. (The administrative data show it was $58.4 \%$ in 2014 and $57.9 \%$ in $2016,{ }^{10}$ but resident surveys indicate much lower rates-ranging from $8 \%$ to $38 \%{ }^{15-17}$ in some rural areas). Considering the complex health system context, we make some recommendations for improving the low quality of services.

\section{Better matching between service package design and funding}

Although the current level of financing and the systems to equalise distribution support the expansion of services to all citizens, they provide limited scope for ensuring the quality of care. The funding made available for EBPHS was determined politically, not based on the analysis of costs. It did not go through a robust priority setting process for selecting a rational services package. Equalisation processes did not sufficiently take into account the different costs and existing service capacity in regions with different levels of development. A study of one province calculated the costs of the EBPHS package as $\$ 7.31$ and $\$ 8.65$ per capita in urban and rural areas respectively. These costs were higher than funding level, which was $\$ 3.97$ for residents in all areas. ${ }^{18}$

To make further progress on quality of services, an explicit and formalised priority setting process should be developed to refine the service package and ensure it reflects better the available funding. This process should also take into account the different needs and costs across regions.

\section{Performance assessment to focus more on quality indicators}

EBPHS has achieved a rapid expansion of the basic services package but some strategies may have compromised quality of care to some extent. For example, the strict and frequent performance assessments and linking the allocation of the funds with performance generated substantial pressure to implement the services package. However, these performance indicators were mainly focused on processes such as developing follow-up lists and filling health record forms, and they might have reduced the incentives of health workers to focus on improving quality of care and health out-

\section{Box 1: Public health services in China}

Public health is broadly defined as all social efforts to prevent diseases and improve population health. ${ }^{19}$ In China, however, public health services are usually understood from the perspective of the services or activities provided by public health institutions, which are distinguished from medical services.

Public health institutions-These include centres for disease control and prevention, specialised diseases prevention and control institutions (such as tuberculosis hospitals or institutes of parasitic diseases), maternal and child care institutions, centres for health education, blood centres, and health inspection authorities

Public health services-Prevention and control of communicable and chronic diseases, monitoring and health epidemic emergency response, prevention and control of endemic diseases and environment related disease, maternal and child healthcare, family planning, health education and health surveillance, blood collection and supply, sanitary and health inspection, and basic public health services provided by primary care institutions.

Primary care institutions-Comprising community health centres and stations in urban areas and township hospitals and village clinics in rural areas. They are grassroots institutions providing both public health services and medical services to community residents. ${ }^{20}$ Public health workers within the institutions provide the basic public health services package and clinical doctors provide diagnosis and treatment 


\begin{tabular}{|c|c|c|c|c|c|}
\hline & Lowest & Low & Middle & High & Highest \\
\hline No of provinces & 12 & 10 & 3 & 4 & 2 \\
\hline Average GDP per capita ( $¥$ ) & 45577 & 47589 & 69670 & 99771 & 1278140 \\
\hline$\%$ of budget from national funding & 80 & 60 & 50 & 30 & 10 \\
\hline
\end{tabular}

comes. ${ }^{4}$ More indicators of service quality need to be added to the EBPHS policy to assess the performance of service providers, moving providers' focus from process to the quality of care and health outcomes of residents.

\section{Better integration of public health and} medical services in primary care

The fragmented delivery of the EBPHS service packages has become a bottleneck for realising its potential to improve population health. There are limited synergies between the public health services in EBPHS and routine medical services offered by primary healthcare institutions, reflecting a broader pattern of fragmentation within the Chinese health delivery system $^{2}$ (box 1). For example, the management of non-communicable diseases covered under EBPHS includes developing health records, updating records after follow-ups, and health education but does not include clinical services like prescription and adjustment of medicines. Although the primary care institutions provide all these services, the public health workers (in charge of EBPHS services) and doctors (in charge of medical treatment) work in separate departments and there are limited mechanisms for them to cooperate in providing integrated care for prevention, treatment, and health promotion. This is likely to have hampered the improvement of health outcomes in patients with noncommunicable diseases.

Further progress in meeting the goals of EBPHS would be aided by ensuring that public health workers and medical

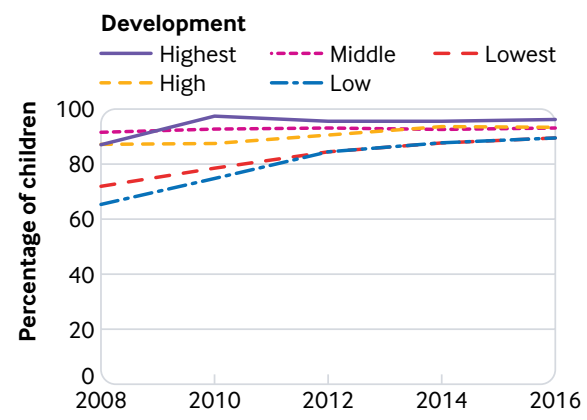

Fig 1 | Proportion of children under 3 years old in China covered by child health surveillance programme by level of development of province, 2008-16 doctors cooperate by working together as a family care team. This will help to improve continuity and quality of management of complex conditions and achieve better population outcomes.

Support from overall health system reforms Finally, the lack of quality in some EBPHS services also stems from some longstanding challenges in China's overall health system. One of the biggest challenges is the lack of qualified health workers in primary care. ${ }^{2}$ This is aggravated by a lack of measures to effectively motivate health workers, ${ }^{21}$ who experienced a higher workload as they began to deliver new services under EBPHS. ${ }^{223}$ Consequently, the further improvement of the EBPHS has to rely on reforms of the overall health system, especially strengthening and motivating the primary care workforce, integration of health service delivery, and consolidation of financing arrangements.

\section{Wider implications}

EBPHS is a multifaceted policy that has been implemented throughout China since 2009 , with the goal of strengthening public health system and accelerating progress to universal health coverage. Given its broad scope, its precise effect is difficult to assess, and the outcomes have varied for different types of service categories. There are indications that EBPHS has improved coverage and reduced inequalities between lower and higher developed provinces. However, the quality of some services, such as management of non-communicable disease, remains low despite increased access.

China's experience with the EBPHS policy provides important lessons for other low and middle income countries seeking

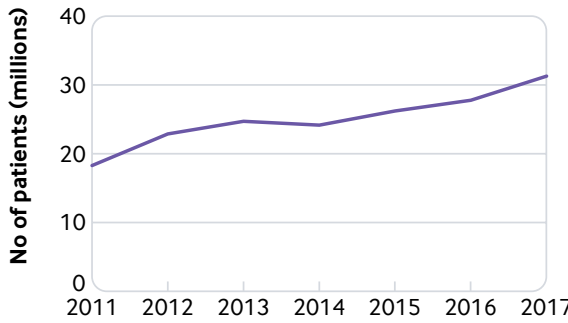

Fig 2 | Total numbers of patients with type 2 diabetes in China receiving managed care, ${ }^{9}$ 2011-17

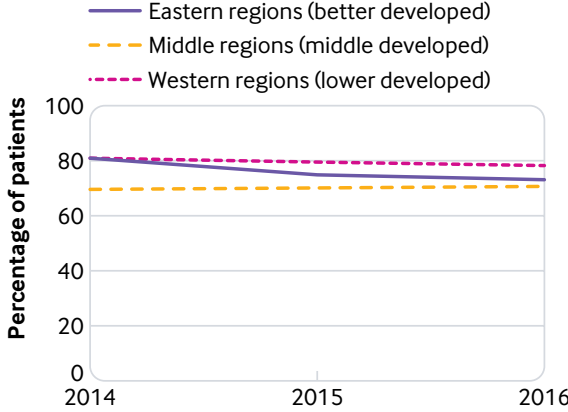

Fig 3 | Percentage of patients with type 2 diabetes receiving managed care according to development of province, 2014-16 ${ }^{10}$

to expand essential health services to achieve universal health coverage. It shows the importance of strong government commitment, reflected in guarantees for government financing and enacting of appropriate regulations and incentives for effective implementation. However, simply equalising the funding levels and ensuring that the service package is universally available and a duty for providers is not enough. With rapid expansion, the challenges of maintaining quality become more acute and can potentially undermine the ultimate health outcomes of the scheme. It is vital to monitor and address the use and quality of services for different population subgroups in order to improve the health of the entire population.

We thank Dr Xuan Zhao from Peking University China Center for Health Development Studies for help in data analysis.

Contributors and sources:BY drafted the manuscript with support from other authors. DB has expertise in health system strengthening and provided inputs on the drafting and revising of this manuscript. ST has much research experiences in health systems and infectious disease control programmes in China and other LMICs; he contributed to the framework and viewpoints discussion in this manuscript. JG works in the monitoring of universal health coverage, health information, and evidence informed policy making and contributed to the framework and key concepts definition used in this manuscript. YG has long research experience in universal health coverage and primary healthcare; she contributed to the framework, data sources and viewpoints discussion in this manuscript.

Competing interests: We have read and understood BMJ policy on declaration of interests and have no interests to declare.

Provenance and peer review: Commissioned; externally peer reviewed.

This article is part of series proposed by the Peking University China Center for Health Development Studies and commissioned by The BMJ. The BM] retained full editorial control over external peer review, editing, and publication of these articles. Open access fees are funded by Peking University Health Science Center.

Beibei Yuan, associate professor ${ }^{1}$

Dina Balabanova, associate professor ${ }^{2}$ 
Jun Gao, regional adviser ${ }^{3}$

Shenglan Tang, professor ${ }^{4}$

Yan Guo, professor ${ }^{5}$

${ }^{1}$ China Center for Health Development Studies, Peking University, Beijing, China

${ }^{2}$ London School of Hygiene and Tropical Medicine, London, UK

${ }^{3}$ World Health Organization, Manila, Philippines

${ }^{4}$ Duke University, Durham, NC, USA

${ }^{5}$ School of Public Health, Peking University, Beijing. China

Correspondence to: B Yuan

beibeiyuan@bjmu.edu.cn

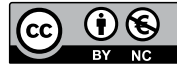

This is an Open Access article distributed in accordance with the Creative Commons Attribution Non Commercial (CC BY-NC 4.0) license, which permits others to distribute, remix, adapt, build upon this work non-commercially, and license their derivative works on different terms, provided the original work is properly cited and the use is non-commercial. See: http://creativecommons.org/ licenses/by-nc/4.0/.

\section{D) Check for updates}

1 Ministry of Health. Opinions on promoting the gradual equalization of basic public health services. 2009. \#http://www.gov.cn/ztzl/ygzt/content_1661065.htm

2 Meng Q, Mills A, Wang L, Han Q. What can we learn from China's health reforms?BMJ 2019;365:12349. doi:10.1136/bmj.l2349

3 Yang L, Sun L, Wen L, et al. Financing strategies to improve essential public health equalization and its effects in China. Int J Equity Health 2016;15:194. doi:10.1186/s12939-016-0482-x

4 Qing J. Progress in basic public health service projects in China. Chin J Publ Health 2017;33:1289-97.
5 National Health Commission. Chinese Health Statistical Yearbook 2010-2018. Peking Union Medical College Press, 2010-2018.

6 National Basic Public Health Services Code. Versions 1-3 2009-17

7 World Health Organization, International Bank for Reconstruction and Development, World Bank. Tracking universal health coverage: 2017 global monitoring report. 2017. https://www.who.int/ healthinfo/universal_health_coverage/report/ 2017/en/

82016 Health system reform progress monitoring report. 2017. http://www.nhc.gov.cn/tigs/ygjb/201 707/72dbee11426a48cfbe66325c20099c5f.sht $\mathrm{ml}$ ? from=singlemessage\&isappinstalled $=0 \# 10006$ weixin-1-52626-6b3bffd01fdde4900130bc5a275 $1 \mathrm{~b} 6 \mathrm{~d} 1$

9 International Diabetes Federation (IDF). IDF Diabetes Atlas. 8th ed. 2017. https://diabetesatlas.org/ resources/2017-atlas.html

10 Wang Z, Yang J, Chen X, et al. Evaluation on implementation effect of National Basic Public Health Service Project. Chinese Health Economics 2018;37:63-6.

11 Zhao Y, Crimmins EM, Hu P, et al. Prevalence, diagnosis, and management of diabetes mellitus among older Chinese: results from the China Health and Retirement Longitudinal Study. Int J Public Health 2016;61:347-56. doi:10.1007/s00038-015-0780-x

12 Wang F, Li Y, Ding X, Dai T. The national essential public health services project in China: progress and equity. Chinese Journal of Health Policy 2013;6:9-14.

13 Deng C, Hao X, Jiang Y, et al. Research on the progress and equity of disease control projects in basic public health services. Chinese Health Economic 2018:37:64-8.

14 Center for Diseases Control, National Health and Family Planning Commission. National disease monitoring system death-surveillance, China death-surveillance data. Military Medical Science Press,Science and Technology of China Press, 2015.

15 Liu X, Li Y, Li L, et al. Prevalence, awareness, treatment, control of type 2 diabetes mellitus and risk factors in Chinese rural population: the RuralDiab study. Sci Rep 2016;6:31426. doi:10.1038/ srep31426

16 Liu X, Wang L, Wang P, et al. The dynamics of type 2 diabetes mellitus prevalence and management rates among rural population in Henan Province, China. J Diabetes Res 2017;2017:9092759. doi:10.1155/2017/9092759

17 Yang F, Qian D, Chen J, et al, LWS Project Group. Prevalence, awareness, treatment and control of diabetes mellitus in rural China: results from Shandong Province. Diabet Med 2016;33:454-8. doi: $10.1111 / \mathrm{dme} .12842$

18 Yin D, Wong ST, Chen W, et al. A model to estimate the cost of the national essential public health services package in Beijing, China. BMC Health Serv Res 2015;15:222. doi:10.1186/s12913-0150902-4

19 Wu Y. Strengthening public health system and creating a new situation in China's health work. National Health Work Conference. Chinese Health Quality Managemen t 2003;53(4):5-11.

20 World Health Organization Regional Office for the Western Pacific. People's Republic of China health system review. Manila : WHO Regional Office for the Western Pacific Health Systems in Transition, 2015.

21 Ma X, Wang H, Li Y, Shi L, Liu X. Incentivising China's primary health care providers. BMJ 2019;365:12406. doi:10.1136/bmj.12406

22 Li X, Cochran C, Lu J, et al. Understanding the shortage of village doctors in China and solutions under the policy of basic public health service equalization: evidence from Changzhou. Int J Health Plann Manage 2015;30:E42-55. doi:10.1002/ hpm. 2258

23 Zhou H, Zhang W, Zhang S, et al. Health providers' perspectives on delivering public health services under the contract service policy in rural China: evidence from Xinjian County. BMC Health Serv Res 2015;15:75. doi:10.1186/s12913-015-0739-x

Cite this as: $B M J$ 2019;365:12358

http://dx.doi.org/10.1136/bmj.12358 